\title{
CdS Nanoparticles with a Thermoresponsive Polymer: Synthesis and Properties
}

\begin{abstract}
Aslam Khan
King Abdullah Institute for Nanotechnology, King Saud University, Riyadh 11451, Saudi Arabia

Correspondence should be addressed to Aslam Khan, aslampoly@gmail.com

Received 6 February 2012; Accepted 16 April 2012

Academic Editor: Anukorn Phuruangrat

Copyright () 2012 Aslam Khan. This is an open access article distributed under the Creative Commons Attribution License, which permits unrestricted use, distribution, and reproduction in any medium, provided the original work is properly cited.

This paper describes the synthesis of thermoresponsive colloidal nanocomposites based on CdS and poly( $N$-isopropylacrylamide). The CdS nanoparticles were prepared at room temperature from cadmium chloride and sodium sulfide salts in the presence of an organic ligand, 3-mercaptopropionic acid (MPA). The as-prepared MPA-bound CdS nanoparticles were stable for more than 30 days and exhibited good optical properties. The effect of various ratios of MPA/Cd ${ }^{2+}$ and $\mathrm{H}_{2} \mathrm{O} / \mathrm{DMF}$ (dimethylformamide) on the particle size of the CdS nanoparticles was investigated using UV-vis absorption measurements. Transmission electron microscopy studies showed that the particle sizes were approximately $4 \mathrm{~nm}$ in diameter, which is consistent with the size obtained using UV-vis spectroscopy. The CdS nanocomposite showed a temperature-responsive phenomenon as its temperature increased from 20 to $45^{\circ} \mathrm{C}$.
\end{abstract}

\section{Introduction}

Colloidal nanoparticles (NPs) have attracted extensive scientific and industrial interest as a consequence of their highly size-dependent properties and their unique optical and electronic features [1-4]. These properties have led to the potential application of colloidal NPs in light-emitting devices [5], photonic crystals [6], and biological labels [710]. CdS nanoparticles represent a material that can be both fabricated and functionalized with biomolecules in a single step. Consequently, much effort has been devoted to the synthesis of these small quantum-sized particles. CdS NPs have been successfully synthesized in a variety of media, such as nonaqueous solvents [11-13], reverse micelles [14, 15], vesicles [16], zeolites $[17,18]$, and others $[19,20]$. Some of the synthetic methods use $\mathrm{Cd}^{2+}$ and $\mathrm{H}_{2} \mathrm{~S}$ in separate phases that are unevenly mixed and result in the uneven formation and aggregation of CdS NPs. Some methods involve mixing $\mathrm{Cd}^{2+}$ with $\mathrm{S}^{2-}$ at a rate that is faster than their homogenous mixing rate; the inhomogeneity at early stages of these methods results in a broadening of the size distribution of the products. In addition, the preparation and deoxygenation of fresh $\mathrm{H}_{2} \mathrm{~S}$ aqueous solutions are necessary in these methods to avoid the formation of colloidal sulfur and other species that result from the instability of $\mathrm{Na}_{2} \mathrm{~S}$ as a precursor.

Environmentally responsive polymers have been a subject of great interest in the past decade due to their versatile applications [21]. Such polymers are sometimes termed "smart" because their properties allow them to react in a specific way to external stimuli. Hence, such smart materials can respond to various parameters, such as temperature [22,23], $\mathrm{pH}[24,25]$, ionic strength [26], or magnetic field strength [27]. Applications of these systems include drug delivery [28, 29], biosensing [30], chemical separation [31], biomaterials [32], and catalysis [33-35]. Poly( $N$-isopropylacrylamide) (pNIPAAm) is the most extensively used thermoresponsive polymer [23]. pNIPAAm exhibits a low critical solution temperature (LCST) (or phase-separation temperature) of approximately $32^{\circ} \mathrm{C}$ in aqueous solution, below which the polymer is hydrophilic and above which it becomes hydrophobic. It is possible to increase the functionality of polymers by finding the right balance of hydrophilic and hydrophobic comonomers. Polymers can also be tuned to a desired temperature range by polymerization with a more hydrophilic comonomer (which raises the LCST) or a hydrophobic comonomer (which lowers the LCST) [36]. 
In this study, CdS NPs and pNIPAAm composites are prepared and the interaction between the amide group of isopropylacrylamide from the polymer backbone and the carboxyl group from the modified CdS NPs is investigated. The resultant composites based on CdS@pNIPAAm are expected to be thermoresponsive because pNIPAAm is a typical smart polymer that undergoes the coil-to-globules transition in water at its LCST of approximately $32^{\circ} \mathrm{C}$. In addition, the optical properties of MPA-coated CdS NPs in DMF are thoroughly investigated.

\section{Materials and Methods}

2.1. Materials. Cadmium chloride, sodium sulfide, 2,2'azodiis-obutyronitrile (AIBN), and dry $N, N$-dimethylformamide (DMF) were supplied by Merck (India) and used as received. $N$-Isopropylacrylamide was obtained from Aldrich, recrystallized in hexane, and dried under vacuum before use. 3-Mercaptopropionic acid (MPA) was purchased from Sigma-Aldrich. The water used in all experiments was purified to a resistance of $10 \mathrm{M} \Omega$ (Milli-Q Reagent Water System, Millipore Corporation) and filtered through a $0.2 \mu \mathrm{m}$ filter to remove any particulate matter.

2.2. Synthesis of MPA-Modified CdS Nanoparticles. In the first step, $2.5 \mathrm{mmol}$ of cadmium chloride monohydrate $\left(\mathrm{CdCl}_{2} \cdot \mathrm{H}_{2} \mathrm{O}\right)$ was dissolved in $3 \mathrm{~mL}$ of deionized water. The cadmium chloride solution was then mixed with $5.0 \mathrm{mmol}$ of MPA in $30 \mathrm{~mL}$ of DMF and stirred vigorously for $10 \mathrm{~min}$. In the second step, $3 \mathrm{~mL}$ of aqueous sodium sulfide solution $\left(\mathrm{Na}_{2} \mathrm{~S}: 1.67 \mathrm{mmol}\right)$ was slowly added dropwise to the cadmium chloride solution with stirring. After the solutions were mixed, the resulting solution immediately turned yellow and cloudy. Then the reaction was allowed to continue for an additional $4 \mathrm{~h}$ at room temperature, and the yellow solution gradually became transparent. At the end, the product was centrifuged $(10,000 \mathrm{rpm})$, washed several times with DMF, and finally washed with water.

2.3. Synthesis of pNIPAAm. pNIPAAm was synthesized using free-radical polymerization at $70^{\circ} \mathrm{C}$ as follows: $1.18 \mathrm{~g}$ (10.4 mmol) of $N$-isopropylacrylamide was added to $12 \mathrm{~mL}$ of DMF. The reaction medium was carefully degassed and maintained under a nitrogen purge. Then, $9.15 \times 10^{-6} \mathrm{~mol}$ of AIBN was dissolved in the reaction mixture. The solution was degassed by bubbling with nitrogen for $30 \mathrm{~min}$. The reaction mixture was refluxed at $70^{\circ} \mathrm{C}$ for $7 \mathrm{~h}$ under nitrogen. Upon completion of the reflux, the product was precipitated upon the addition of diethyl ether and then dried in vacuum. The number-average molecular weight $(\mathrm{Mn})$ and molecular weight distribution $(\mathrm{Mw})$ of the polymer were measured using GPC and were found to be $M n=25,890$ and $M w /$ $M n=1.08$, respectively.

2.4. Preparation of CdS@pNIPAAm Nanocomposites. In a typical synthesis, $10 \mathrm{~mL}$ of $0.05 \%$ polymer solution in water was placed in a $25 \mathrm{~mL}$ beaker and stirred for $3 \mathrm{~h}$ at room temperature for complete dissolution. To this solution, $500 \mu \mathrm{L}$ of $0.2 \mathrm{mmol} / \mathrm{L}$ freshly prepared CdS NPs in water was added. This mixture was stirred for $1 \mathrm{~h}$. This solution was used for further characterization studies.

2.5. Characterization. The molecular weight of the polymer was determined using gel permeation chromatography (GPC) (Waters 515, MA, USA) on an instrument that was equipped with a differential refractometer detector (Waters 2410, MA, USA). THF served as the mobile phase with a flow rate of $1 \mathrm{~mL} / \mathrm{min}$. Number-average molecular weights and polydispersity indices were calculated from a calibration curve using a series of polystyrene standards (Polymer Laboratories, MA, USA) with molecular weights that ranged from 1350 to 151,700 . The UV-vis absorption spectra were detected with a Varian Cary 50 Bio UV-vis spectrophotometer over a wavelength range of 320-650 nm using DMF as a solvent. All of the samples for UV-vis were centrifuged prior to measurement by adding an excess amount of water to remove the impurities and redispersing them in DMF. Transmission electron microscope (TEM) studies of the samples were performed by depositing a drop of sample that was dispersed in DMF onto a carbon-coated copper grid and allowing it to air dry at room temperature. A JEOL JEM-2100 transmission electron microscope operating at an accelerating voltage of $200 \mathrm{kV}$ was used for these measurements. The photoluminescence (PL) spectra were measured at room temperature on an FA-375 luminescence spectrometer (Thermospectronic, USA) operating with a $365 \mathrm{~nm}$ laser beam as a light source. The powder X-ray diffraction (XRD) patterns were acquired on a Bruker-AXS D8 ADVANCE X-ray diffractometer at a scanning rate of 0.02 steps $/ \mathrm{s}$ from 20 to $70^{\circ}$ with $\mathrm{Cu} \mathrm{K} \alpha$ radiation $(\lambda=0.1542 \mathrm{~nm})$. The Fourier-transform infrared (FTIR) spectra were scanned over the range of $400-4000 \mathrm{~cm}^{-1}$ with a potassium bromide plate on a Perkin-Elmer Spectrum-One spectrophotometer. To measure the LCSTs of the colloidal CdS@pNIPAAm nanocomposite and pNIPAAm, the cloud-point method (turbidimetry) was employed. Briefly, the LCST of aqueous colloidal solutions $((\mathrm{CdS})=0.20 \mathrm{mmol} / \mathrm{L})$ were measured on a UV-vis spectrophotometer (Lambda 45, Perkin Elmer) at $500 \mathrm{~nm}$ using a peltier-thermostattable 9-cell holder; the solution temperature was increased from 20 to $45^{\circ} \mathrm{C}$ at $1^{\circ} \mathrm{C}$ intervals. At each temperature, the samples were stabilized for $10 \mathrm{~min}$ prior to the measurements. The LCST values of the colloids were determined at the temperature where the sample exhibited an optical transmittance of 50\%.

\section{Results and Discussion}

It is well known that the optical and electronic properties of NPs are dominated by carrier confinement (electron/hole), which results in a size dependence of their optical properties, including light absorption, photoluminescence (PL), electroluminescence (EL), and cathodoluminescence (CL) [37]. Here, the typical synthesis of $\mathrm{COOH}$-modified CdS NPs involves the reaction between cadmium and sulfur ions in the presence of organic ligands containing mercapto groups (Scheme 1). The electron-deficient cadmium atoms on the surfaces of semiconductors serve as binding sites to anchor organic ligands and to hinder the further growth 

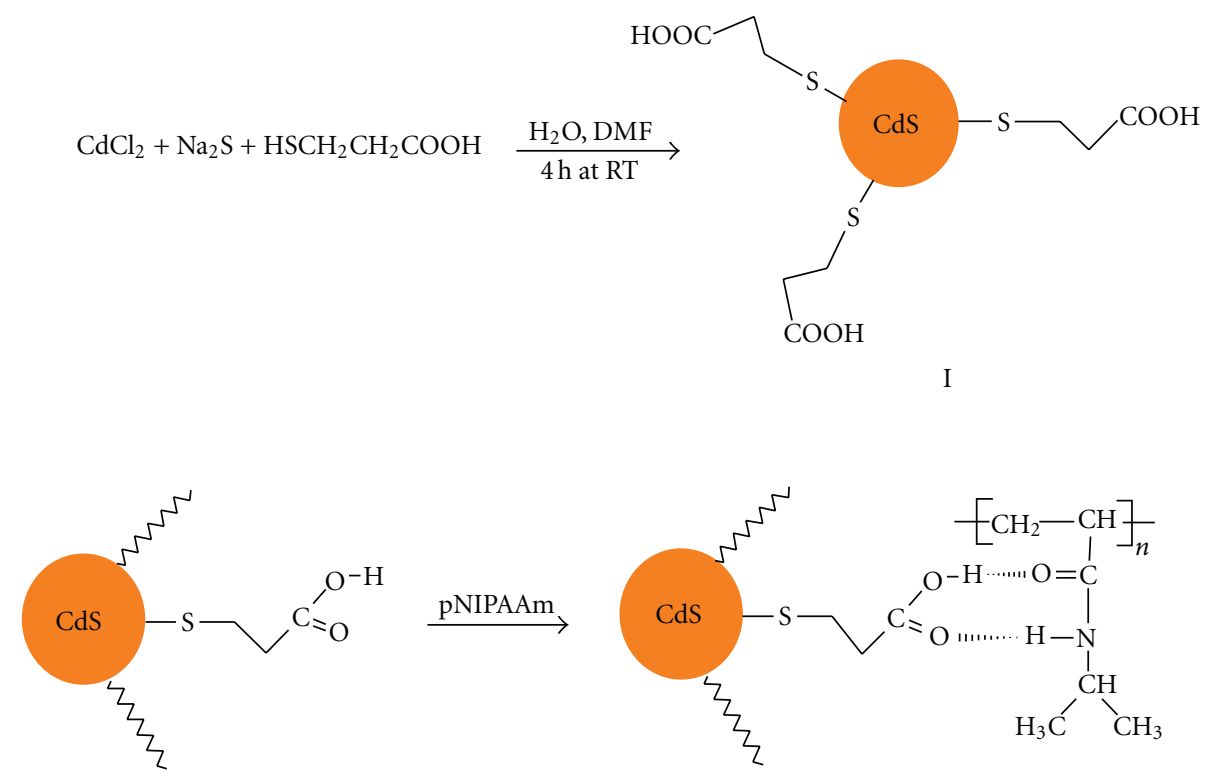

I

SCHEME 1: Synthesis of MPA-bound CdS NPs and CdS/polymer nanocomposite hybrids.

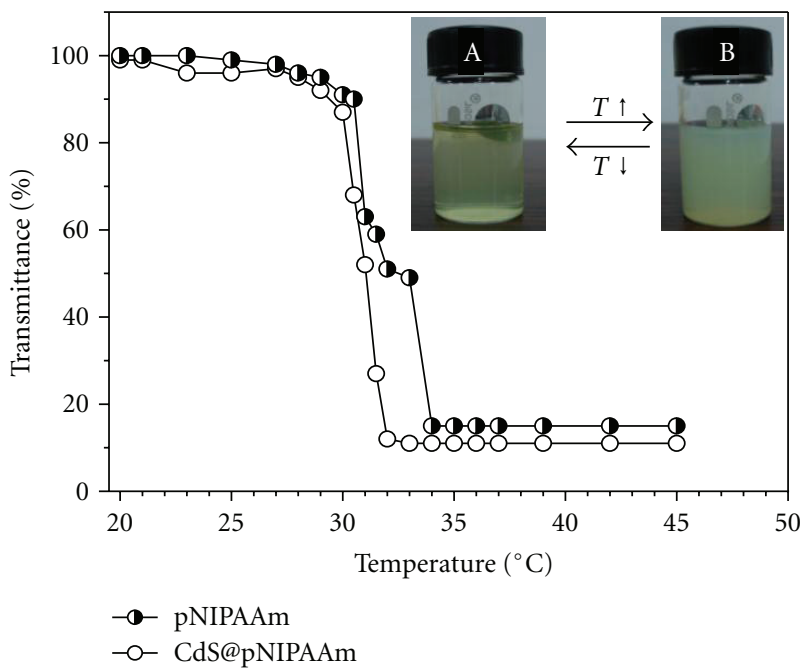

FIGURE 1: Plot of transmittance of a colloidal solution of CdS@pNIPAAm and pNIPAAm (pure polymer) dispersed in water as a function of temperature at a wavelength of $500 \mathrm{~nm}$; concentration of $\mathrm{CdS}=0.2 \mathrm{mmol} / \mathrm{L}$. Insets: photographs of the colloidal solution of CdS@pNIPAAm in water at (A) $25^{\circ} \mathrm{C}$ and (B) $40^{\circ} \mathrm{C}$.

of crystal grains. These effects result in the formation of nanosized crystals. Winter et al. [38] reported using MPA to prepare CdS NPs from cadmium chloride and sodium sulfide. However, the reaction had to be performed at high $\mathrm{pH}$ for approximately $4 \mathrm{~h}$. In the present method, CdS NPs were prepared at neutral $\mathrm{pH}$ to improve their dispersibility in water.

Figure 1 shows a typical transmittance versus temperature curve of a CdS@pNIPAAm nanocomposite sample and pNIPAAm alone. The CdS@pNIPAAm composites are

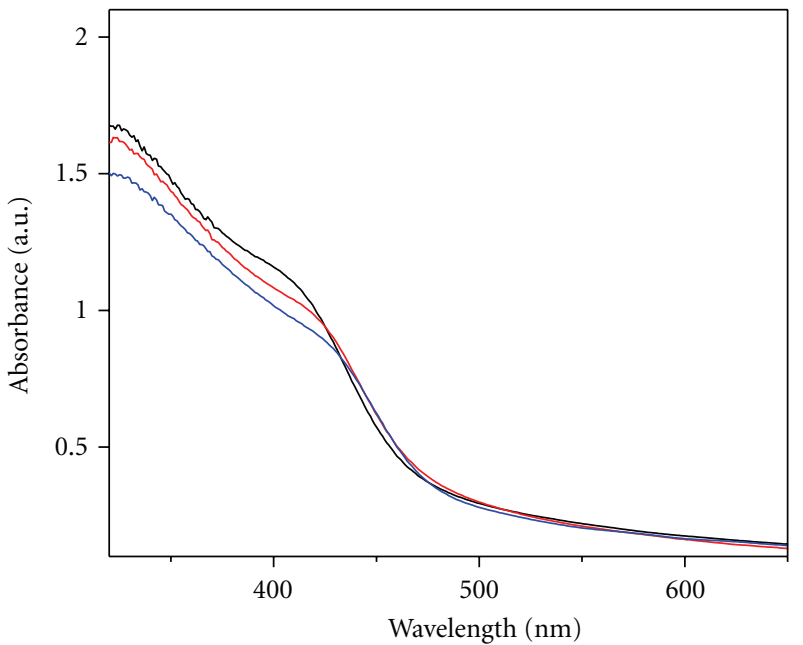

$\mathrm{MPA} / \mathrm{Cd}^{2+}$

$$
\begin{array}{r}
-2 / 1 \mathrm{mmol} \\
-\quad 1 / 1 \mathrm{mmol}
\end{array}
$$$$
\text { - } 0.5 / 1 \mathrm{mmol}
$$

FIGURE 2: UV-vis absorption spectra of CdS NPs prepared at $\mathrm{H}_{2} \mathrm{O}$ / DMF; $0.2 / 1.0 \mathrm{w} / \mathrm{w}$ and different molar ratios of MPA/Cd ${ }^{2+}$; reaction time $3 \mathrm{~h}$ at $25^{\circ} \mathrm{C}$.

thermoresponsive in water, as are pNIPAAm. The phasetransition temperature or LCST was observed at approximately $30.7^{\circ} \mathrm{C}$ for the CdS@pNIPAAm composite. Below the phase-transition temperature or LCST, the pNIPAAm is hydrophilic (due to the formation of individual random-coil chains) and the colloidal dispersion of the CdS@pNIPAAm composite is transparent, as shown in inset photograph $\mathrm{A}$ in Figure 1. Above the LCST, the pNIPAAm gradually becomes hydrophobic (due to the formation of a single-chain globule 


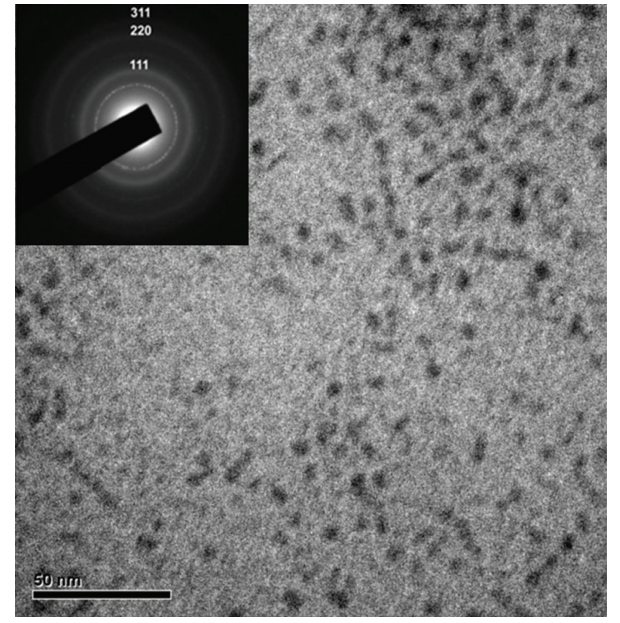

Figure 3: Typical transmission electron microscopy image of CdS NPs dispersed in DMF. Scale bar represents $50 \mathrm{~nm}$. Inset: SAED pattern of the same CdS nanoparticles.

or multichain aggregation) and collapses onto the surface of the CdS nanoparticles $[23,39,40]$; the colloidal dispersion becomes turbid during this process, as shown in inset photograph B in Figure 1. When the colloidal dispersion of CdS@pNIPAAm composite solutions were kept at room temperature $\left(\sim 25^{\circ} \mathrm{C}\right)$, that is, below the LCST value, for overnight after the phase-transition experiments, precipitation started, and the obtained solid was difficult to redisperse. The LCST value of the CdS/pNIPAAm composite decreases to $30.7^{\circ} \mathrm{C}$ compared to LCST values of approximately $32.0^{\circ} \mathrm{C}$ for the pure pNIPAAm (Figure 1) and approximately $32.6^{\circ} \mathrm{C}$ for the MPA-pNIPAAm mixture without CdS (data not shown). When the MPA-bound CdS@pNIPAAm composite is dispersed in aqueous solution, several interactions between the polymer and the MPA-bound CdS NPs can occur. These interactions can be either van der Waals or H-bonding interactions (inter- or intra-molecular H-bonding) [39]. The polymer itself can form H-bonds between its own $\mathrm{CONH}$ groups and water molecules. Similarly, the $-\mathrm{COOH}$ groups of the MPA could form $\mathrm{H}$-bonds with water as well as with the polymer below the LCST. Above the LCST, the polymer shrinks to a form where water molecules are expelled from the network, and when MPA-bound CdS NPs are part of the polymer structures, the $\mathrm{H}$-bonding would primarily occur between the - $\mathrm{COOH}$ groups of the MPAbound CdS NPs and those (along with amide groups) of the polymer. The decrease in the LCST values of the MPAbound CdS@pNIPAAm composite may be influenced by the unbinding or loss of MPA from the composite. It is known that the bond between a metal and sulfide is not very stable at high temperatures [41]. Thus, parts of the MPAbound CdS@pNIPAAm chains possibly disengage from the CdS NPs when the colloidal dispersion is heated above the LCST, which results in a decrease of the LCST value of the composite.

To investigate the effects of ligand concentration on the particle sizes of CdS NPs, the absorbance of CdS nanoparticles prepared with different molar ratios of ligand to $\mathrm{Cd}^{2+}$ was measured using UV-vis spectrophotometry. As shown in Figure 2, a weak blue shift in the maximum absorption band from 422 to $406 \mathrm{~nm}$ occurs as the concentration of organic ligand increases. The absorption peaks of three samples of different molar ratios of ligand to $\mathrm{Cd}^{2+}$ are centered at 406,415 , and $422 \mathrm{~nm}$, respectively. The blue shift is consistent with the quantum confinement effect due to decreasing particle size because the higher concentration of ligand is unfavorable to the nucleation and growth of CdS NPs. The electron-deficient atoms of cadmium on the surface of semiconductors serve as binding sites to anchor organic ligands and to hinder the further growth of crystal grains; these combined effects result in the formation of nanosized crystals. The as-prepared MPA-bound CdS NPs are stable at room temperature, and we did not observe any precipitation over a period of more than $30 \mathrm{~d}$. In the control experiment without MPA as the organic ligand, CdS particles were prepared in the polymer solution and we observed yellow sediments immediately after the addition of $\mathrm{Na}_{2} \mathrm{~S}$. The stability of MPA-bound CdS composite nanoparticles over long storage periods again confirms that the nanoparticles are immobilized by the pNIPAAm molecules. It is reasonable to expect that the complexation between MPA-bound CdS nanoparticles and pNIPAAm chains contributes to the stabilization of CdS nanoparticles within the polymer shell. This point will be discussed in more detail below.

According to Brus, [42] the excitation energy of NPs is inversely proportional to their particle size. The higher energy makes the position of the maximum absorption peak in a NC's UV-vis spectrum shift toward the blue region. The calculated particle size of the CdS NPs prepared with $1 / 1$ molar ratio of $\mathrm{MPA} / \mathrm{Cd}^{2+}$ is $3.89 \mathrm{~nm}$ according to Siu et al. [40], whereas the particle sizes in the other two samples are $3.58 \mathrm{~nm}\left(\mathrm{MPA} / \mathrm{Cd}^{2+}=0.5 / 1 \mathrm{~mol} / \mathrm{mol}\right)$ and $4.14 \mathrm{~nm}\left(\mathrm{MPA} / \mathrm{Cd}^{2+}=2 / 1 \mathrm{~mol} / \mathrm{mol}\right)$. These values are similar to the particle size observed directly from the TEM image and selected-area electron diffraction (SAED) pattern with crystal structure shown in Figure 3, which demonstrates that the mean size of the CdS NPs is approximately $4 \mathrm{~nm}$ and that the particles are thoroughly dispersed in the DMF solution. The results also show that the as-prepared CdS NPs behave as quantum dots.

DMF is used as an organic solvent to enhance the solubility of CdS NPs because they are unavailable in aqueous solution without the addition of DMF. The weight ratio of $\mathrm{H}_{2} \mathrm{O}$ to DMF in the solution also affects the particle size, which can be easily observed through the transparency of the solution. Precipitation of CdS is observed when the weight ratio $\left(\mathrm{H}_{2} \mathrm{O} / \mathrm{DMF}\right)$ exceeds 1.5. The UV-vis absorption spectra of CdS NPs prepared with weight ratios of $\mathrm{H}_{2} \mathrm{O} / \mathrm{DMF}$ ranging from $0.2 / 1.0$ to $0.9 / 1.0$ are presented in Figure 4. With the same reagent concentrations $\left(\mathrm{Cd}^{2+} / \mathrm{S}^{2-}=1 / 0.67 \mathrm{~mol} / \mathrm{mol}\right)$, the absorption peaks of $\mathrm{H}_{2} \mathrm{O} / \mathrm{DMF}$ in weight ratios of $0.2 / 1.0$, 0.5/1.0, and 0.9/1.0 (Figure 4(a)) center at 406, 425, and $428 \mathrm{~nm}$, respectively. The corresponding particle diameters of CdS NPs, calculated according to the method of Yu et al. [43], are 3.58, 4.25, and $4.37 \mathrm{~nm}$, respectively. At higher concentrations of DMF, the absorption band is blue-shifted, which indicates that the DMF concentration affects the size 


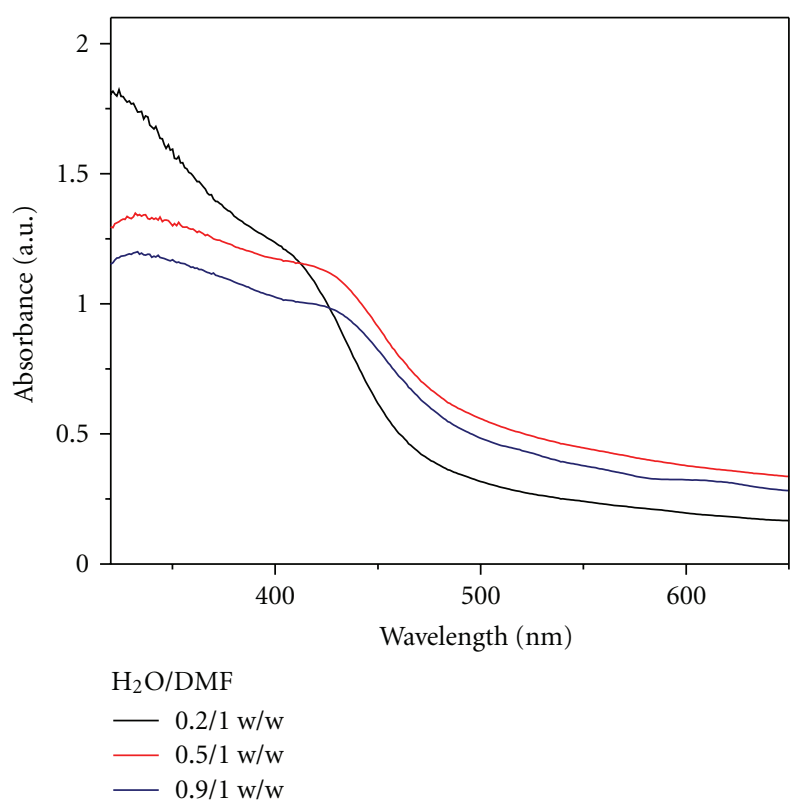

(a)

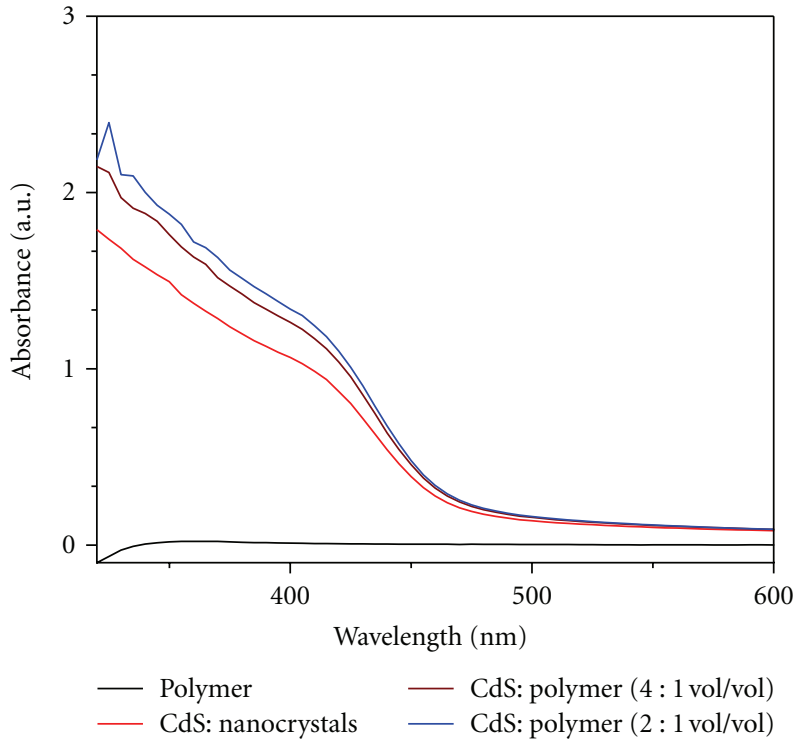

(b)

FIGURE 4: (a) UV-vis absorption spectra of CdS NPs of different weight ratios of $\mathrm{H}_{2} \mathrm{O} / \mathrm{DMF}\left(\mathrm{MPA} / \mathrm{Cd}^{2+}=2.0 / 1.0 \mathrm{mmol}\right)$; reaction time $3 \mathrm{~h}$. (b) UV-vis absorption spectra of polymer, polymer-CdS composites, and CdS NPs diluted in DMF at $25^{\circ} \mathrm{C}$.

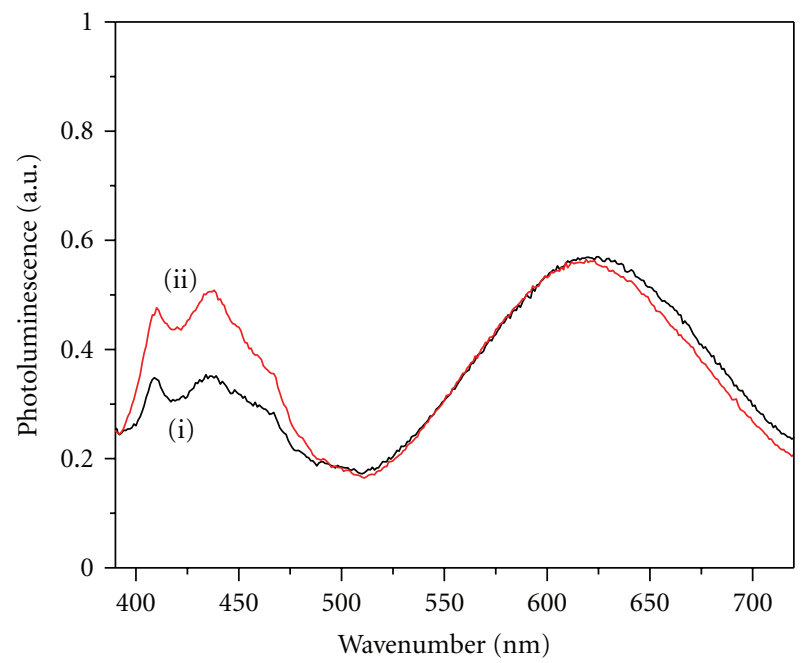

Figure 5: Fluorescence emission spectra of (i) a suspension of MPAmodified CdS NPs, and (ii) CdS $=4.0 \mathrm{wt} \%$ polymer composite with $\lambda_{\text {ex }}=365 \mathrm{~nm}$ at $25^{\circ} \mathrm{C}$.

of the CdS NPs. A slight blue shift (up to $22 \mathrm{~nm}$ ) is caused by the change in the dielectric constant of the environment that surrounds the CdS NPs. As previously reported [4446], the blue shift in the excitonic absorbance spectrum of nanometer-sized semiconductor particles is a phenomenon that is normally attributed to the quantum size effect on band-gap properties and the changing dielectric constant of the surrounding medium.

To confirm that the CdS NPs are well dispersed and bound to the polymer matrix, the UV-vis absorption spectra

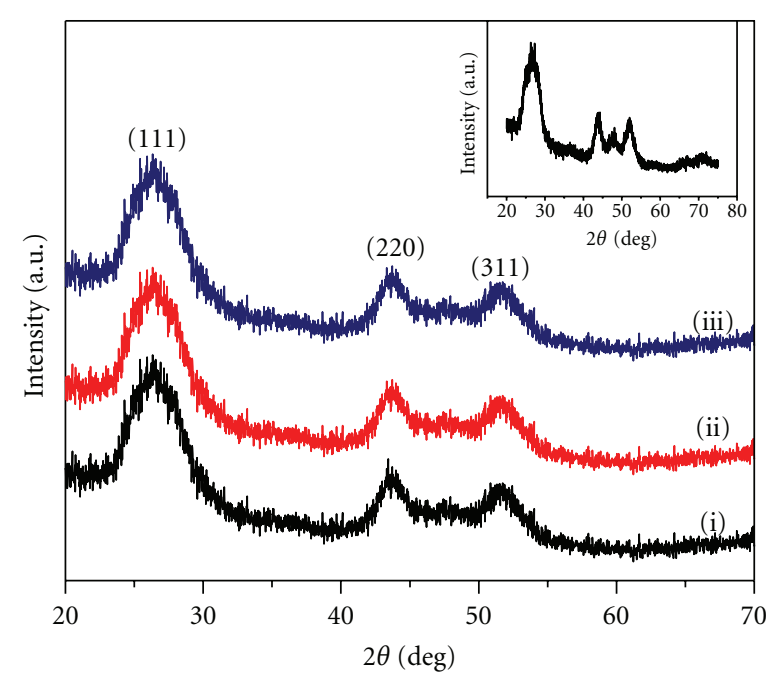

Figure 6: XRD patterns of CdS NC powders fabricated with different MPA concentrations (i) $\mathrm{MPA} / \mathrm{Cd} 2_{+}=2.0 / 1.0 \mathrm{~mol} / \mathrm{mol}$, (ii) $\mathrm{MPA} / \mathrm{Cd} 2_{+}=1.0 / 1.0 \mathrm{~mol} / \mathrm{mol}$, and (iii) $\mathrm{MPA} / \mathrm{Cd} 2_{+}=$ $0.5 / 1.0 \mathrm{~mol} / \mathrm{mol}$; solvent $\mathrm{H}_{2} \mathrm{O} / \mathrm{DMF}=0.2 / 1.0 \mathrm{w} / \mathrm{w}$, reaction time $3 \mathrm{~h}$. Inset shows the XRD pattern of CdS NC powder without addition of MPA.

of polymer-CdS composites with various concentrations of CdS NPs were measured and compared with the spectrum of the pure polymer. Figure 4(b) shows the UV-vis absorption spectra of the pure polymer, polymer-CdS composites (CdS $=2$ and $5 \mathrm{wt} \%$ ), and CdS NPs diluted with DMF. As shown in Figure 4(b), no absorption peak is evident for the pure polymer, whereas an absorption peak can be observed 


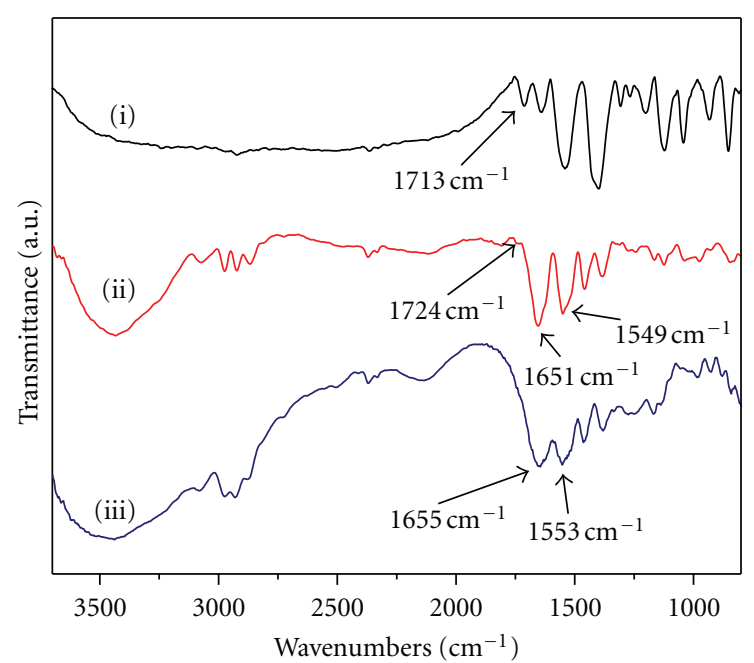

FIGURE 7: FTIR spectra of MPA-modified CdS NPs (i); polymerCdS composite (ii); polymer (iii).

in the polymer-CdS composites and pure CdS NPs at $400 \mathrm{~nm}$; this result indicates that the size of the CdS NPs in the composites does not change and is maintained at approximately $4 \mathrm{~nm}$. In addition, the strength of the absorption peak is enhanced with increased CdS concentration.

As a typical semiconductor, CdS NPs exhibit interesting optical properties. Figure 5 shows the fluorescence emission spectra of the ligand-modified, $\mathrm{COOH}$-coated CdS NC suspension and a polymer composite with excitation at $365 \mathrm{~nm}$. As shown in Figure 5, the characteristic emission of CdS NPs occurs at approximately 410, 445, and $620 \mathrm{~nm}$. The emission at $620 \mathrm{~nm}$ is assigned to electron-hole recombinations at surface traps, whereas the higher-energy emission at 410 and $445 \mathrm{~nm}$ are attributed to recombination from the free excitons state in the interior of the crystallites $[41,47,48]$. Spectrum 5 (ii) shows that an increase in the emission peak strength and bandwidth occurs in the CdSpolymer composite. Usually, the energy and bandwidth of $\mathrm{CdS}$ photoluminescence bands relate to the size and nature of carrier-trap states that are located at the surfaces of NPs. The effect of band broadening may be explained by the surface structure of CdS NPs and the change in their particle sizes when the CdS NPs are bound to the polymer backbone via H-bonds.

To investigate the effect of MPA ligands on the structure of CdS NPs, the samples containing MPA ligands and control samples were characterized using XRD (Figure 6). The XRD patterns of CdS (JCPDS 10-454) with different concentrations of MPA and without MPA ligands exhibit characteristic peaks at scattering angles $\left(2 \theta^{\circ}\right)$ of $26.40,43.90$, and 51.90, which correspond to scattering from the (111), (220), and (311) planes, respectively. The XRD peaks of CdS samples containing MPA broaden, which indicates that the particle sizes of CdS crystals prepared with MPA ligand become smaller. However, the presence of the organic MPA ligand in the preparation of CdS cannot change the structure of the CdS crystals. According to the Scherrer equation [49], the average sizes of the NPs are approximately 3.5, 3.8, and $3.8 \mathrm{~nm}$ based on calculations using the width of the (220) peak for MPA $/ \mathrm{Cd}^{2+}=2 / 1 \mathrm{~mol} / \mathrm{mol}, 1 / 1 \mathrm{~mol} / \mathrm{mol}$, and $0.5 / 1 \mathrm{~mol} / \mathrm{mol}$, respectively.

The FTIR spectra of the CdS NPs, pure polymer, and CdS@pNIPAAm nanocomposites are shown in Figure 7. From the FTIR spectrum of CdS NPs (Figure 7(i)), the peak at $1713 \mathrm{~cm}^{-1}$ represents the $\mathrm{C}=\mathrm{O}$ double-bond stretching vibration in the carboxylic acid groups bound to the CdS particles. The peaks at 1655 and $1553 \mathrm{~cm}^{-1}$ represent the amide I and amide II peaks of pure pNIPAAm, respectively. However, in the spectra of the composites, shifts in the N$\mathrm{H}$ deformation peak of the pNIPAAm network and in the $\mathrm{C}=\mathrm{O}$ stretching peak of the $\mathrm{CdS}-\mathrm{COOH}$-modified composite were observed. The wavenumber of the $\mathrm{N}-\mathrm{H}$ peak decreases from 1655 to $1651 \mathrm{~cm}^{-1}$ and from 1553 to $1549 \mathrm{~cm}^{-1}$ for amide I and II, respectively. The shifts for both peaks are approximately four units to the lower wavenumber. The equipment error is within one unit. The wavenumber of the $\mathrm{C}=\mathrm{O}$ peak in the $\mathrm{CdS}-\mathrm{COOH}$-modified sample shifts from 1713 to $1724 \mathrm{~cm}^{-1}$ in the case of the CdS-polymer composite. This result indicates that there is an interaction between the carboxylic groups of $-\mathrm{COOH}$ and the amide groups of pNIPAAm [49]. Also, the widths of the peaks in the composites increased relative to the $\mathrm{CdS}-\mathrm{COOH}$ modified NPs.

\section{Conclusion}

Nanocomposites of CdS@pNIPAAm with well-tailored optical properties have been prepared via MPA-bound CdS NPs and pNIPAAm. The CdS NPs were obtained using the reaction between cadmium chloride and sodium sulfide in the presence of MPA as the organic ligand. The $\mathrm{COOH}-$ terminated alkyl group attached to the surfaces of the CdS NPs enhances their dispersibility in the solvent, thereby allowing control of the particle size of the NPs. The effect of concentration of the reactants and solvents on the particle size of as-prepared CdS NPs has been thoroughly investigated. The size of CdS NPs characterized with TEM is approximately $4 \mathrm{~nm}$, in good agreement with the calculated data from UV-vis absorption spectra. In addition, the UV-vis absorption band is blue-shifted for the higher concentrations of MPA ligand and DMF, thus indicating that their concentrations are a key factor for the particle size of CdS. The FTIR characterization indicates the formation of a robust bonding between the CdS NPs and the organic ligand. The as-prepared CdS@pNIPAAm particles exhibit a temperatureresponsive behavior and their phase-transition temperature is approximately $30.7^{\circ} \mathrm{C}$.

\section{Acknowledgment}

Financial support from the King Abdul Aziz City for Science and Technology (KACST) under the National Plan for Science and Technology (NPST) scheme (Grant no. 10NAN1008-02) is gratefully acknowledged. 


\section{References}

[1] X. Peng, L. Manna, W. Yang et al., "Shape control of CdSe nanocrystals," Nature, vol. 404, no. 6773, pp. 59-61, 2000.

[2] W. U. Huynh, J. J. Dittmer, and A. P. Alivisatos, "Hybrid nanorod-polymer solar cells," Science, vol. 295, no. 5564, pp. 24252427, 2002.

[3] Z. Y. Tang, N. A. Kotov, and M. Giersig, "Spontaneous organization of single CdTe nanoparticles into luminescent nanowires," Science, vol. 297, no. 5579, pp. 237-240, 2002.

[4] Y. Li, A. Rizzo, R. Cingolani, and G. Gigli, "Bright whitelight-emitting device from ternary nanocrystal composites," Advanced Materials, vol. 18, no. 19, pp. 2545-2548, 2006.

[5] Y. W. Lin, W. L. Tseng, and H. T. Chang, "Using a layer-bylayer assembly technique to fabricate multiply colored films of CdSe CdS and CdTe quantum dots," Advanced Materials, vol. 18, pp. 1381-1386, 2006.

[6] F. Fleischhaker and R. Zentel, "Photonic crystals from coreshell colloids with incorporated highly fluorescent quantum dots," Chemistry of Materials, vol. 17, no. 6, pp. 1346-1351, 2005.

[7] A. Schroedter, H. Weller, R. Eritja, W. E. Ford, and J. M. Wessels, "Biofunctionalization of silica-coated CdTe and gold nanocrystals," Nano Letters, vol. 2, no. 12, pp. 1363-1367, 2002.

[8] J. K. Jaiswal and S. M. Simon, "Potentials and pitfalls of fluorescent quantum dots for biological imaging," Trends in Cell Biology, vol. 14, no. 9, pp. 497-504, 2004.

[9] X. Michalet, F. F. Pinaud, L. A. Bentolila et al., "Quantum dots for live cells, in vivo imaging, and diagnostics," Science, vol. 307, no. 5709, pp. 538-544, 2005.

[10] S. Kim, Y. T. Lim, E. G. Soltesz et al., "Near-infrared fluorescent type II quantum dots for sentinel lymph node mapping," Nature Biotechnology, vol. 22, no. 1, pp. 93-97, 2004.

[11] R. Rossetti, R. Hull, J. M. Gibson, and L. E. Brus, "Excited electronic states and optical spectra of $\mathrm{ZnS}$ and $\mathrm{CdS}$ crystallites in the $\approx 15$ to $50 \AA$ size range: evolution from molecular to bulk semiconducting properties," The Journal of Chemical Physics, vol. 82, no. 1, pp. 552-559, 1985.

[12] R. Rossetti, J. L. Ellison, J. M. Gibson, and L. E. Brus, "Size effects in the excited electronic states of small colloidal CdS crystallites," The Journal of Chemical Physics, vol. 80, no. 9, pp. 4464-4469, 1984.

[13] J. J. Ramsden, S. E. Webber, and M. Grätzel, "Luminescence of colloidal CdS particles in acetonitrile and acetonitrile/water mixtures," Journal of Physical Chemistry, vol. 89, no. 13, pp. 2740-2743, 1985.

[14] C. Petit and M. P. Pileni, "Synthesis of cadmium sulfide in situ in reverse micelles and in hydrocarbon gels," Journal of physical chemistry, vol. 92, no. 8, pp. 2282-2286, 1988.

[15] P. Lianos and J. K. Thomas, "Cadmium sulfide of small dimensions produced in inverted micelles," Chemical Physics Letters, vol. 125, no. 3, pp. 299-302, 1986.

[16] H. J. Watzke and J. H. Fendler, "Quantum size effects of in Situ generated colloidal CdS particles in dioctadecyldimethylammonium chloride surfactant vesicles," Journal of Physical Chemistry, vol. 91, no. 4, pp. 854-861, 1987.

[17] R. D. Stramel, T. Nakamura, and J. K. Thomas, "Photophysical and photochemical properties of CdS with limited dimensions," Journal of the Chemical Society, Faraday Transactions, vol. 84, no. 5, pp. 1287-1300, 1988.

[18] Y. Wang and N. Herron, "Optical properties of CdS and PbS clusters encapsulated in zeolites," Journal of Physical Chemistry, vol. 91, no. 2, pp. 257-260, 1987.
[19] G. Henshaw, I. P. Parkin, and G. Shaw, "Convenient, lowenergy synthesis of metal sulfides and selenides; PbE, Ag2E, $\mathrm{ZnE}, \mathrm{CdE}(\mathrm{E}=\mathrm{S}$, Se)," Chemical Communications, no. 10, pp. 1095-1096, 1996.

[20] M. Ohtaki, K. Oda, K. Eguchi, and H. Arai, "Preparation of nanosized CdS particles using decomposition of P2S5 in a non-aqueous solvent," Chemical Communications, no. 10, pp. 1209-1210, 1996.

[21] S. Nayak and L. Andrew Lyon, "Soft nanotechnology with soft nanoparticles," Angewandte Chemie, vol. 44, no. 47, pp. 76867708, 2005.

[22] R. Pelton, "Temperature-sensitive aqueous microgels," Advances in Colloid and Interface Science, vol. 85, no. 1, pp. 1-33, 2000.

[23] A. Khan, "Preparation and characterization of $N$-isopropylacrylamide/acrylic acid copolymer core-shell microgel particles," Journal of Colloid and Interface Science, vol. 313, no. 2, pp. 697-704, 2007.

[24] C. D. Jones and L. A. Lyon, "Synthesis and characterization of multiresponsive core-shell microgels," Macromolecules, vol. 33, no. 22, pp. 8301-8306, 2000.

[25] D. Dupin, S. Fujii, S. P. Armes, P. Reeve, and S. M. Baxter, "Efficient synthesis of sterically stabilized $\mathrm{pH}$-responsive microgels of controllable particle diameter by emulsion polymerization," Langmuir, vol. 22, no. 7, pp. 3381-3387, 2006.

[26] W. McPhee, K. C. Tam, and R. Pelton, "Poly( $N$-isopropylacrylamide) latices prepared with sodium dodecyl sulfate," Journal of Colloid And Interface Science, vol. 156, no. 1, pp. 2430, 1993.

[27] M. Zrínyi, "Intelligent polymer gels controlled by magnetic fields," Colloid and Polymer Science, vol. 278, no. 2, pp. 98-103, 2000.

[28] M. Das, S. Mardyani, W. C. W. Chan, and E. Kumacheva, "Biofunctionalized $\mathrm{pH}$-responsive microgels for cancer cell targeting: rational design," Advanced Materials, vol. 18, no. 1, pp. 80-83, 2006.

[29] K. S. Soppimath, D. C. W. Tan, and Y. Y. Yang, "pH-triggered thermally responsive polymer core-shell nanoparticles for drag delivery," Advanced Materials, vol. 17, no. 3, pp. 318-323, 2005.

[30] Z. Hu, Y. Chen, C. Wang, Y. Zheng, and Y. Li, "Polymer gels with engineered environmentally responsive surface patterns," Nature, vol. 393, no. 6681, pp. 149-152, 1998.

[31] H. Kawaguchi and K. Fujimoto, "Smart latexes for bioseparation,” Bioseparation, vol. 7, no. 4-5, pp. 253-258, 1998.

[32] N. Sahiner, W. T. Godbey, G. L. McPherson, and V. T. John, "Microgel, nanogel and hydrogel-hydrogel semi-IPN composites for biomedical applications: synthesis and characterization," Colloid and Polymer Science, vol. 284, no. 10, pp. 1121-1129, 2006.

[33] A. Biffis, N. Orlandi, and B. Corain, "Microgel-stabilized metal nanoclusters: size control by microgel nanomorphology," Advanced Materials, vol. 15, no. 18, pp. 1551-1555, 2003.

[34] A. Biffis and L. Minati, "Efficient aerobic oxidation of alcohols in water catalysed by microgel-stabilised metal nanoclusters," Journal of Catalysis, vol. 236, no. 2, pp. 405-409, 2005.

[35] Y. Lu, Y. Mei, M. Drechsler, and M. Ballauff, "Thermosensitive core-shell particles as carriers for Ag nanoparticles: modulating the catalytic activity by a phase transition in networks," Angewandte Chemie, vol. 45, no. 5, pp. 813-816, 2006.

[36] H. Feil, Y. H. Bae, J. Feijen, and S. W. Kim, "Effect of comonomer hydrophilicity and ionization on the lower critical solution temperature of $\mathrm{N}$-isopropylacrylamide copolymers," Macromolecules, vol. 26, no. 10, pp. 2496-2500, 1993. 
[37] J. Rodriguez-Viejo, K. F. Jensen, H. Mattoussi, J. Michel, B. O. Dabbousi, and M. G. Bawendi, "Cathodoluminescence and photoluminescence of highly luminescent $\mathrm{CdSe} / \mathrm{ZnS}$ quantum dot composites," Applied Physics Letters, vol. 70, no. 16, pp. 2132-2134, 1997.

[38] J. O. Winter, N. Gomez, S. Gatzert, C. E. Schmidt, and B. A. Korgel, "Variation of cadmium sulfide nanoparticle size and photoluminescence intensity with altered aqueous synthesis conditions," Colloids and Surfaces A, vol. 254, no. 1-3, pp. 147$157,2005$.

[39] A. Murugadoss, A. Khan, and A. Chattopadhyay, "Stabilizer specific interaction of gold nanoparticles with a thermosensitive polymer hydrogel," Journal of Nanoparticle Research, vol. 12, no. 4, pp. 1331-1348, 2010.

[40] M. Siu, H. Y. Liu, X. X. Zhu, and C. Wu, "Formation of mesoglobular phase of amphiphilic copolymer chains in dilute solution: effect of comonomer composition," Macromolecules, vol. 36, no. 6, pp. 2103-2107, 2003.

[41] J. R. Lakowicz, I. Gryczynski, Z. Gryczynski, K. Nowaczyk, and C. J. Murphy, "Time-resolved spectral observations of cadmium-enriched cadmium sulfide nanoparticles and the effects of DNA oligomer binding," Analytical Biochemistry, vol. 280, no. 1, pp. 128-136, 2000.

[42] L. E. Brus, "A simple model for the ionization potential, electron affinity, and aqueous redox potentials of small semiconductor crystallites," The Journal of Chemical Physics, vol. 79, no. 11, pp. 5566-5571, 1983.

[43] W. W. Yu, L. Qu, W. Guo, and X. Peng, "Experimental determination of the extinction coefficient of CdTe, CdSe, and CdS nanocrystals," Chemistry of Materials, vol. 15, no. 14, pp. 28542860, 2003.

[44] E. Rabani, B. Hetényi, B. J. Berne, and L. E. Brus, "Electronic properties of CdSe nanocrystals in the absence and presence of a dielectric medium," Journal of Chemical Physics, vol. 110, no. 11 , pp. 5355-5369, 1999.

[45] A. Deshpande, P. Shah, R. S. Gholap, and N. M. Gupta, "Interfacial and physico-chemical properties of polymer-supported CdS ZnS nanocomposites and their role in the visible-light mediated photocatalytic splitting of water," Journal of Colloid and Interface Science, vol. 333, no. 1, pp. 263-268, 2009.

[46] T. Vossmeyer, L. Katsikas, M. Giersig et al., "CdS nanoclusters: synthesis, characterization, size dependent oscillator strength, temperature shift of the excitonic transition energy, and reversible absorbance shift," Journal of Physical Chemistry, vol. 98, no. 31, pp. 7665-7673, 1994.

[47] A. Phuruangrat, N. Ekthammathat, T. Thongtem, and S. Thongtem, "Glycolthermal synthesis and characterization of hexagonal CdS round microparticles in flower-like clusters," Journal of Alloys and Compounds, vol. 509, no. 41, pp. 1015010154, 2011.

[48] Z. Dai, J. Zhang, J. Bao, X. Huang, and X. Mo, "Facile synthesis of high-quality nano-sized CdS hollow spheres and their application in electrogenerated chemiluminescence sensing," Journal of Materials Chemistry, vol. 17, no. 11, pp. 1087-1093, 2007.

[49] A. L. Patterson, "The scherrer formula for X-ray particle size determination," Physical Review, vol. 56, no. 10, pp. 978-982, 1939. 

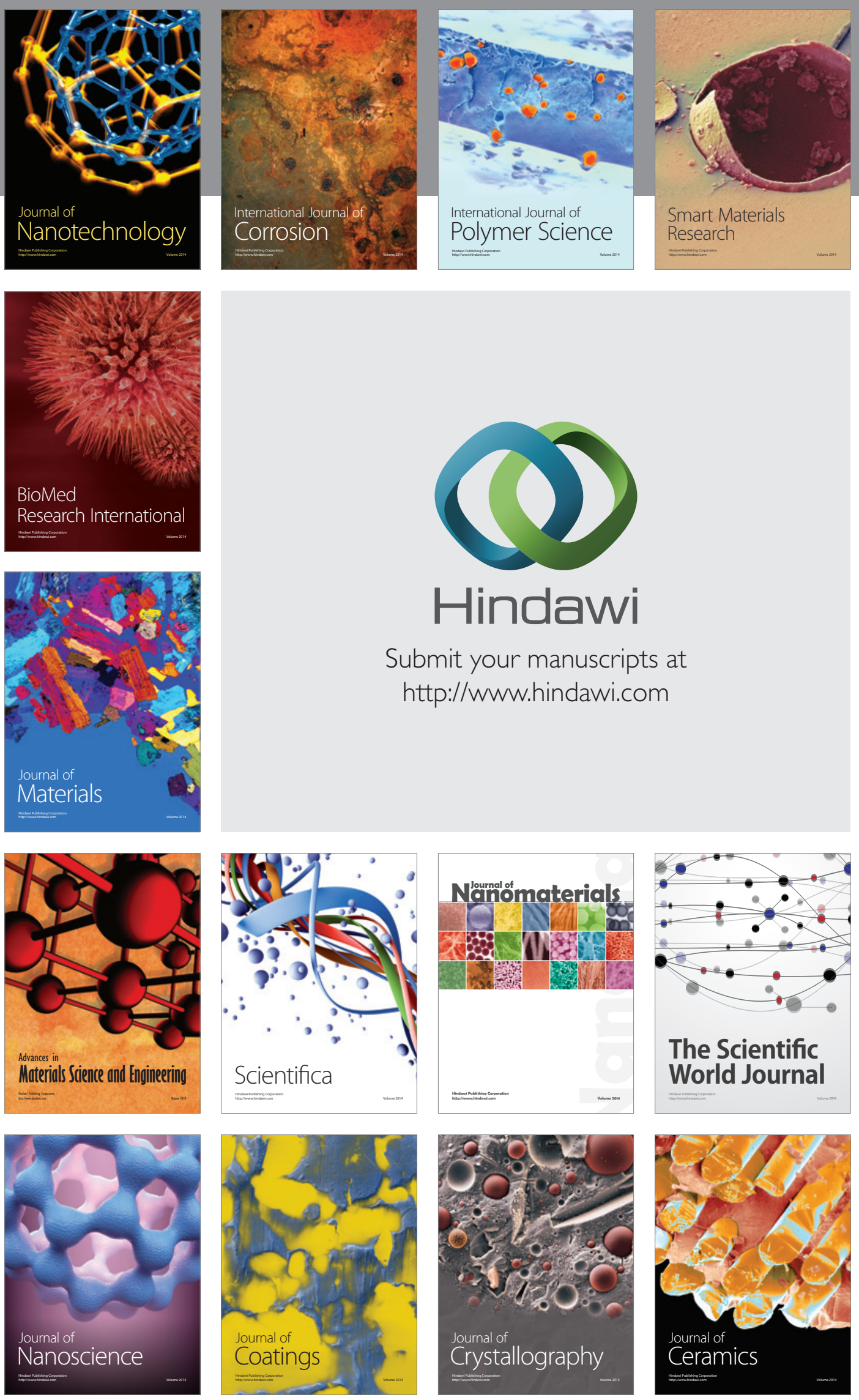

The Scientific World Journal

Submit your manuscripts at

http://www.hindawi.com

\section{World Journal}

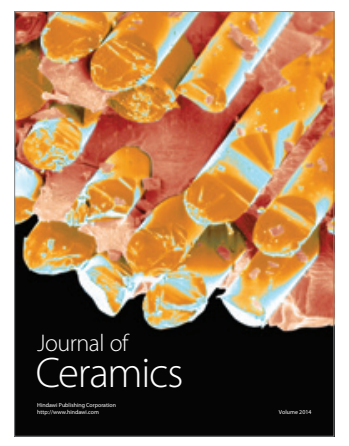

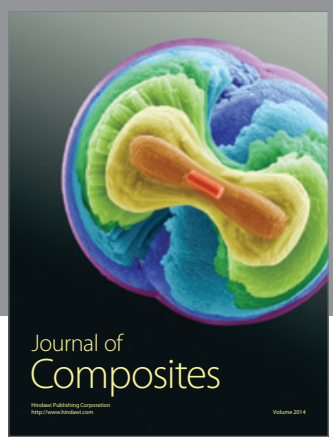
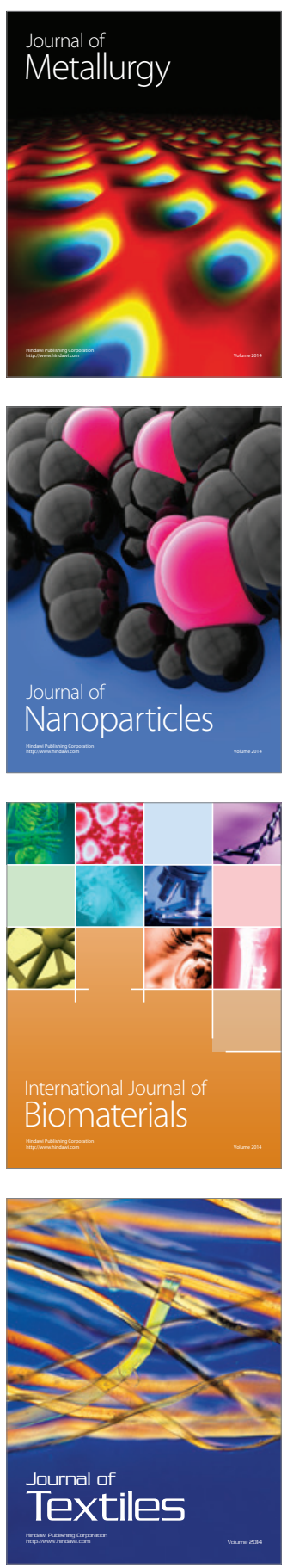